\title{
Polisiklik Aromatik Hidrokarbon (PAH) Di Sekitar Muara Sungai Musi Sumatera Selatan
}

\author{
Wike Ayu Eka Putri ${ }^{1 *}$, Anna Ida Sunaryo Purwiyanto ${ }^{1}$, Fitri Agustriani ${ }^{1}$, Fauziyah ${ }^{1}$, \\ Lilik Maslukah ${ }^{2}$, Yulianto Suteja ${ }^{3}$
}

\author{
${ }^{1} J u r u s a n$ Ilmu Kelautan, Fakultas Matematika dan Ilmu Pengetahuan Alam, Universitas Sriwijaya \\ Jl. Raya Palembang-Prabumulih Km.32. Inderalaya-Sumatera Selatan 30862 Indonesia \\ ${ }^{2}$ Departemen Oseanografi, Fakultas Perikanan dan Ilmu Kelautan, Universitas Diponegoro \\ Jl. Prof. H. Soeadarto S.H, Tembalang, Semarang, Jawa Tengah 50275 Indonesia \\ ${ }^{3}$ Program Studi Ilmu Kelautan, Fakultas Kelautan dan Perikanan, Universitas Udayana \\ Jl. Kampus Bukit Jimbaran Bali 80361 Indonesia \\ Email : wike.aep@gmail.com
}

\begin{abstract}
Abstrak
Muara Sungai Musi dan Pulau Payung adalah kawasan bagian hilir Sungai Musi yang menerima banyak masukan limbah dan bahan pencemar akibat aktifitas di sepanjang aliran sungai. Polisiklik aromatik hidrokarbon $(\mathrm{PAH})$ adalah salah satu komponen pencemar organik yang keberadaannya mengancam kehidupan biota perairan. Penelitian ini bertujuan untuk mengidentifikasi keberadaan senyawa PAH pada sampel air laut dan sedimen yang berasal dari Muara Sungai Musi dan sekitar Pulau Payung. Pengambilan sampel dilakukan pada bulan Juli 2019. Contoh air laut diambil dengan water sampler pada 5 stasiun penelitian dan contoh sedimen diambil menggunakan ekman grab pada 8 stasiun penelitian. Kadar PAH dianalisa dengan High Performance Liquid Chromatography (HPLC), cara kerja merujuk pada APHA (2017) 6440 B divalidasi. Hasil penelitian menunjukkan bahwa kandungan PAH total dalam sampel air Muara Sungai Musi dan sekitar Pulau Payung berkisar antara batas minimum deteksi alat $(<0,004)-0,0,62$ ppb. Adapun kandungan PAH total dalam sampel sedimen berkisar antara 11,92-558,41 ppb. Secara keseluruhan terlihat bahwa kandungan PAH dalam sampel air dan sedimen yang berasal dari Sungai Musi dan sekitar Pulau Payung masih aman bagi organisme.
\end{abstract}

Kata kunci : PAH, Polisiklik aromatik hidrokarbon, Pulau Payung, Muara Sungai Musi

Abstract

Polycyclic Aromatic Hydrocarbons (PAH) Around Musi River Estuary, South Sumatra

Musi River Estuary and Payung Island are the downstream areas of the Musi River which receive a lot of inputs of waste and pollutants due to activities along the river flow. Polycyclic aromatic hydrocarbons (PAHs) is one component of organic pollutants which dangerous for the aquatic organism. This study aims to identify the PAHs compounds in seawater and sediment samples from the Musi River Estuary and around Payung Island. Sampling was carried out in July 2019. Seawater samples were taken with a water sampler and sediment samples were taken using ekman grab at 7 research stations. PAH levels were analyzed by High Performance Liquid Chromatography (HPLC), the method refers to APHA (2017) 6440 B. The results showed that the PAH content in the Muara River Musi water samples and around Payung Island ranged from under detection limit $(<0,004)-0.62 \mathrm{ppb}$. The PAH content in sediment samples ranged from 11.92$558.41 \mathrm{ppb}$. Overall PAHs content in water and sediment samples from the Musi River and around Payung Island are still good for the aquatic organism.

Keywords : PAH, Polisiklik aromatik hidrokarbon, Payung Island, Musi River Estuary 


\section{PENDAHULUAN}

Muara Sungai Musi dan sekitar Pulau Payung merupakan salah satu ekosistem estuaria yang kaya akan keragaman biota. Kawasan ini berbatasan langsung dengan Selat Bangka dan termasuk kedalam zona penangkapan ikan yang menjadi andalan Provinsi Sumatera Selatan. Aktifitas perikanan tangkap banyak dijumpai di kawasan ini, beberapa hasil tangkapan yang dominan adalah udang, ikan pelagis kecil dan ikanikan yang hidup di dasar perairan. Pemanfaatan di sepanjang aliran sungai menyebabkan kawasan muara rentan mengalami pencemaran. Beberapa laporan hasil penelitian terkait bahan pencemar di sekitar kawasan pesisir timur Sumatera Selatan telah di publikasikan. Logam berat ditemukan terakumulasi pada beberapa komponen yang ada di sepanjang aliran Sungai Musi hingga muara, meliputi komponen air (terlarut dan tersuspensi dan sedimen) (Putri et al, 2015), komponen biotik seperti plankton (Putri dan Purwiyanto, 2016) serta ikan-ikan yang hidup di kawasan tersebut (Putri et $a l$, 2016). Kondisi ekologis di daerah Muara Sungai Musi diperkirakan akan semakin menurun akibat meningkatnya kegiatan pemanfaatan wilayah sekitar perairan. Aktifitas industri, pertanian dan perkebunan, daerah pelabuhan dan transportasi serta pemanfaatan daerah aliran sungai sebagai kawasan pemukiman, pada akhirnya akan berdampak terhadap keseimbangan ekosistem. Hal ini tidak dapat dibiarkan terjadi mengingat kawasan Pesisir Banyuasin termasuk di dalamnya Muara Sungai Musi merupakan salah satu sentra perikanan tangkap di Sumatera Selatan.

Polisiklik aromatik hidrokarbon (PAH) adalah salah satu bahan pencemar organik persisten yang keberadaannya di lingkungan perairan berbahaya bagi organisme karena bersifat karsinogenik. Senyawa PAH tersebar luas di alam, bentuknya terdiri dari beberapa rantai siklik aromatik dan bersifat hidrofobik (Khozanah dan Yogaswara, 2017). Berdasarkan jumlah cincin aromatiknya, PAH dapat dibagi menjadi dua jenis yaitu Low Molecular Weight (LMW) dengan cincin aromatik $\leq 4$ dan High Molecular Weight (HMW) dengan cincin aromatik lebih dari 4. Terbatasnya informasi tentang keberadaan bahan pencemar organik yang bersifat persisten di kawasan Muara Sungai Musi melandasi dilakukannya penelitian ini. Penelitian serupa telah pernah dilakukan di Muara Sungai Banyuasin dan menemukan bahwa PAH ditemukan pada sampel air dan sedimen di kawasan tersebut dalam jumlah kecil (Putri et al, 2020). Oleh karena itu dipandang penting untuk melakukan penelitian tentang PAH di sekitar Muara Sungai Musi dan sekitar Pulau Payung agar melengkapi informasi kualitas air terutama bahan pencemar persisten di kawasan tersebut.

\section{MATERI DAN METODE}

Penelitian dilaksanakan selama periode MeiSeptember 2019. Lokasi penelitian di sekitar Pulau Payung dan sekitar Muara Sungai Musi, Kabupaten Banyuasin, Provinsi Sumatera Selatan. Pengambilan contoh air dilakukan pada lima stasiun pengamatan (kode stasiun A), adapun contoh sedimen diambil pada delapan stasiun pengamatan (kode stasiun S) yang diharapkan mewakili lokasi penelitian (Gambar 1).

Sampel air dan sedimen untuk analisa PAH diambil masing-masing sebanyak $500 \mathrm{ml}$ dan 500 mg menggunakan water sampler dan ekman grab. Selanjutnya sampel dimasukkan ke dalam botol kaca yang dilapisi aluminium foil kemudian ditutup rapat untuk menghindari kontaminasi (APHA 2017). Sampel disimpan dalam cool box dengan suhu kurang lebih $4^{\circ} \mathrm{C}$ selama transportasi menuju Laboratorium ICBB-Bogor (Indonesian Center for Biodiversity and Biotechnology). Selanjutnya di laboratorium, sampel air dan sedimen dianalisa kandungan PAH menggunakan HPLC dengan prosedur merujuk pada APHA (2017) 6440 B divalidasi. Hasil pengukuran dinyatakan dalam (ppb). Data air dan sedimen yang didapatkan selanjutnya ditabulasikan dalam tabel, dibandingkan dengan baku mutu dari Keputusan Menteri Negara Lingkungan Hidup (2004) dan dibahas secara deskriptif.

\section{HASIL DAN PEMBAHASAN}

Hidrokarbon aromatik merupakan senyawa organik yang tersebar luas di alam. Bentuknya terdiri dari beberapa rantai siklik aromatik dan bersifat hidrofobik. Zakaria et al., (2006) menyatakan bahwa PAH dapat memasuki ekosistem sungai melalui beberapa sumber dan jalur. Sumber utama berasal dari pembakaran kayu dan batubara, knalpot kendaraan bermotor serta pembangkit panas dan listrik. Hidrokarbon merupakan salah satu kontaminan yang harus mendapatkan perhatian serius karena keberadaannya di alam dapat memberikan pengaruh buruk bagi manusia dan lingkungan. 


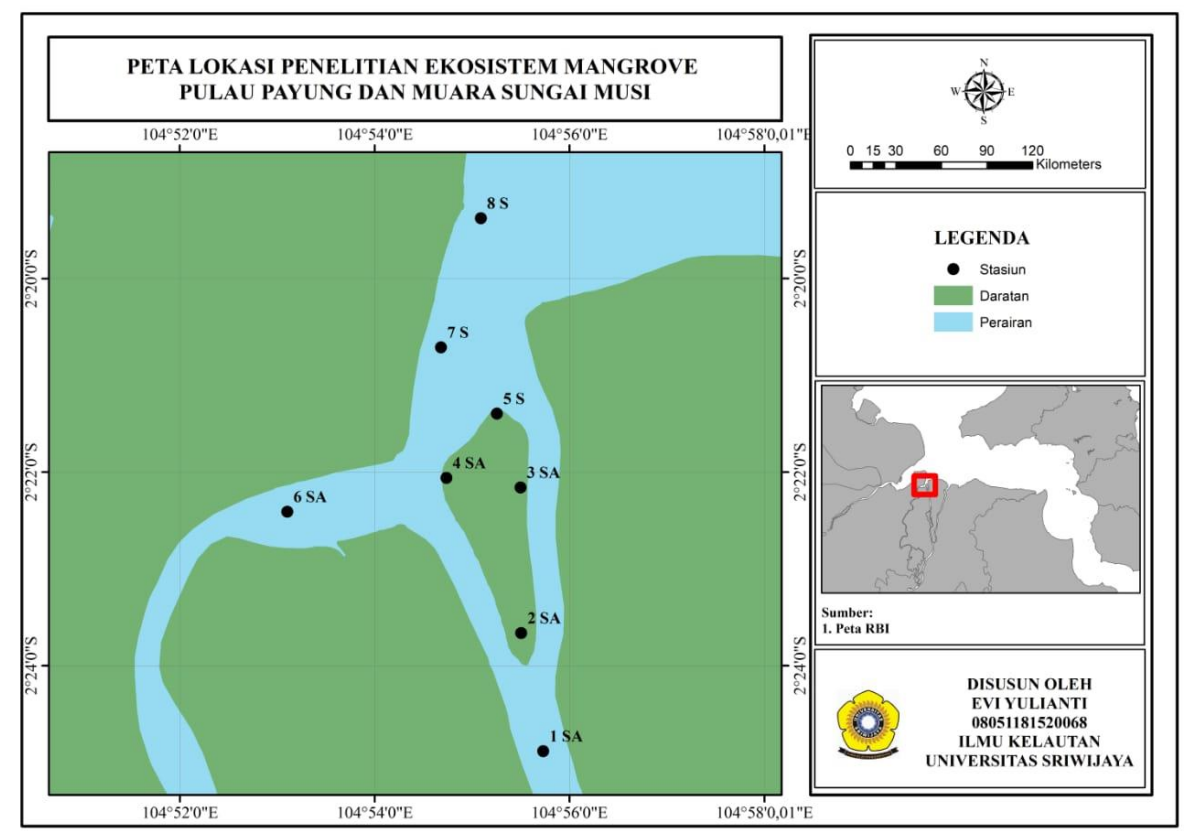

Gambar 1. Lokasi Stasiun Penelitian

Minyak dan turunannya merupakan salah satu contoh dari hidrokarbon yang banyak digunakan manusia dan sangat potensial mencemari lingkungan. Hasil penelitian menemukan empat jenis PAH yang dijumpai di kolom air yang berasal dari Muara Sungai Musi dan sekitar Pulau Payung. Keempat jenis tersebut adalah Napthalene, Fluoanthrene, Pyrene dan Dibenzo(a,h) anthracene (Tabel 1).

Jenis naphthalene hanya ditemukan pada stasiun 3, 6 dan 8 dengan konsentrasi pada masingmasing stasiun berturut-turut adalah $0,15 \mathrm{ppb}, 0,20$ ppt dan 0-0,48 ppb (Tabel 1). Selanjutnya jenis Fluoanthrene dan Pyrene yang ditemukan hanya pada stasiun 6 masing-masing dengan konsentrasi $0,02 \mathrm{ppb}$ dan $0,01 \mathrm{ppb}$. Jenis terakhir yang ditemukan adalah fraksi Dibenzo(a,h) anthracene pada stasiun 6 dan 8 dengan konsentrasi masingmasing 0,09 ppb dan 0,14 ppb. Fraksi lainnya tidak ditemukan pada sampel air di sekitar Muara Sungai Musi dan Pulau Payung (konsentrasinya berada dibawah detection limit $(<0,008 \mathrm{ppb})$. Adapun pada stasiun 1 dan 2, tidak terdapat satu jenis PAH pun yang ditemukan.

Secara umum terlihat bahwa konsentrasi PAH total pada sampel air paling tinggi terdapat pada stasiun 8 yang terletak di kawasan muara Sungai Musi (0,62 ppb) (berada di mulut muara yang mengarah ke laut). Selanjutnya ditemukan pada stasiun 6 (yang terletak di bagian dalam Sungai Telang) dengan konsentrasi 0,32 ppb.
Kemudian Stasiun 3 (terletak di bagian belakang Pulau Payung) dengan nilai 0,15 ppb. Terdapat perbedaan konsentrasi PAH antar stasiun pengamatan yang dapat disebabkan oleh adanya perbedaan arah dan kecepatan arus. Edward (2014) menyatakan bahwa arah dan kecepatan arus yang selalu berubah menyebabkan pola penyebaran PAH tidak merata di permukaan laut. Seperti halnya bahan pecemar lainnya, PAH yang terdapat di kolom perairan (baik yang terlarut maupun tersuspensi) berpotensi terbawa dan terdistribusi ke tempat lain disebabkan oleh arus. Kadar PAH total dalam sampel air yang ditemukan di Muara Sungai Musi lebih kecil dari nilai ambang batas aman untuk kehidupan biota laut yakni $0,003 \mathrm{ppm}$ atau $3 \mathrm{ppb}$ (Keputusan Menteri Negara Lingkungan Hidup, 2004). Meskipun demikian, kondisi ini tetap harus mendapat perhatian serius mengingat keberadaan PAH yang dapat menjadi ancaman bagi biota perairan.

Berbeda dengan konsentrasi PAH dalam sampel air, jenis PAH yang ditemukan pada sampel sedimen lebih banyak ( 9 jenis) dengan konsentrasi total PAH juga dalam jumlah yang lebih tinggi (Tabel 2). Jenis PAH yang ditemukan (9 jenis) yaitu Napthalene, Acenaphthylene, Fluorene, Phenanthrene, Anthracene, Fluoanthrene, Pyrene, Chrysene dan Dibenzo(a,h) anthracene. Pada stasiun 1, PAH jenis Phenanthrene ditemukan sebanyak 34,57 ppb, sedangkan konsentrasi PAH jenis lainnya ditemukan dibawah batas deteksi alat 
$(<0,004 \mathrm{ppb})$. Selanjutnya pada stasiun 2, konsentrasi PAH jenis Napthalene sebesar 3,53 ppb, Fluorene 5,49 ppb, Phenanthrene 56,57 ppb, Fluoanthrene sebesar 15,70 ppb, Pyrene 15,35 ppb dan Dibenzo(a,h) anthracene 2,95 ppb. Stasiun 3 mengandung PAH jenis Napthalene sebesar 71,29 $\mathrm{ppb}$, Fluorene 3,60 ppb, Pyrene 9,51 ppb dan Chrysene 2,61 ppb. Untuk stasiun 4, terdapat 5 jenis PAH yang ditemukan yaitu Napthalene 44,17 ppb, Phenanthrene 3,05 ppb, Fluoanthrene 10,88 ppb, Pyrene 11,86 ppb, dan Benzo(a) anthracene 1,41 ppb. Pada stasiun 5 terdapat lebih sedikit (3) jenis PAH yang dijumpai yaitu Napthalene 7,07 $\mathrm{ppb}$, Fluorene 3,19 ppb dan Dibenzo(a,h) anthracene 1,66 ppt. Adapun pada stasiun 6 terdapat 5 jenis $\mathrm{PAH}$, berturut-turut dalah Napthalene 8,64 ppb, Fluorene 16,04 ppb, Phenanthrene 229,53 ppb, Fluoanthrene 46,67 ppb dan Pyrene 41,67 ppb. Stasiun 7 memiliki 6 jenis $\mathrm{PAH}$ dengan konsentrasi masing-masingnya adalah Napthalene 304,24 ppb, Acenaphthylene $3,68 \mathrm{ppb}$, Fluorene 15,49 ppb, Phenanthrene $165,38 \mathrm{ppb}$, Anthracene 5,59 ppb dan Pyrene 54, $31 \mathrm{ppb}$. Yang terakhir adalah stasiun 8, ditemukan 7 jenis PAH yaitu Napthalene 330,99 ppb, Acenaphthylene 3,41 ppb, Fluorene 16,04 ppb, Phenanthrene 128,58 ppb, Fluoanthrene 38,04 ppb, Pyrene 32,46 ppb dan Chrysene 8,89 ppb.

Konsentrasi PAH pada sampel sedimen berkisar antara 11,92-558,41 ppb. Konsentrasi terendah ditemukan pada stasiun 5 (11,92 ppb) yang terletak pada bagian terluar Pulau Payung dan berbatasan langsung dengan laut terbuka, selanjutnya pada stasiun 1 ( $34,57 \mathrm{ppb})$, stasiun 4 sebesar 71,38 ppb, stasiun 3 (87,02 ppb) dan stasiun 2 (99,59 ppb). Konsentrasi PAH dengan nilai tertinggi ditemukan pada stasiun $8(558,41$ ppb), selanjutnya stasiun $7(548,70 \mathrm{ppb})$ dan stasiun $6342,54 \mathrm{ppb}$.

Kadar PAH total ini lebih rendah dari nilai ambang batas kandungan PAH dalam sedimen yang diperkenankan oleh ANZEEC/ARMCANZ (Simpson et al., 2005) yaitu 4000 ppb. Oleh sebab itu dapat disimpulkan bahwa konsentrasi PAH total dalam sedimen di sekitar Muara Sungai Musi dan Pulau Payung belum melebihi ambang batas yang diperkenankan. Meskipun demikian, hal ini perlu dipantau secara terus menerus agar tidak terjadi kontaminasi PAH dalam jumlah yang lebih tinggi sehingga dikhawatirkan akan terserap oleh produk hasil perikanan terutama yang mendiami dasar perairan. Edward (2014) menyebutkan bahwa senyawa PAH dapat terakumulasi dalam tubuh hewan tingkat rendah hingga mencapai kadar yang tinggi, karena sukar dicerna dalam tubuhnya. Lebih lanjut Nasher et al., 2013 juga menyebutkan bahwa PAH dengan mudah diserap dan terakumulasi dalam biota laut atau terserap pada partikel padat tersuspensi, mengendap ke dasar perairan dan masuk ke rantai makanan.

Tabel 1. Jenis dan konsentrasi PAH pada sampel air di lokasi penelitian

\begin{tabular}{clccccc}
\hline \multirow{2}{*}{ No } & \multicolumn{1}{c}{ Jenis PAH } & \multicolumn{5}{c}{ Stasiun Penelitian dan Konsentrasi PAH (ppb) } \\
\cline { 3 - 6 } & & \multicolumn{1}{c}{2} & 3 & 6 & \multicolumn{1}{c}{8} \\
\hline 1 & Napthalene & $<0.0404$ & $<0.0404$ & 0,15 & 0.2 & 0,48 \\
2 & Acenaphthylene & $<0.0404$ & $<0.0404$ & $<0.0404$ & $<0.0404$ & $<0.0404$ \\
3 & Acenaphtene & $<0.0404$ & $<0.0404$ & $<0.0404$ & $<0.0404$ & $<0.0404$ \\
4 & Fluorene & $<0.0404$ & $<0.0404$ & $<0.0404$ & $<0.0404$ & $<0.0404$ \\
5 & Phenanthrene & $<0.0404$ & $<0.0404$ & $<0.0404$ & $<0.0404$ & $<0.0404$ \\
6 & Anthracene & $<0.0404$ & $<0.0404$ & $<0.0404$ & $<0.0404$ & $<0.0404$ \\
7 & Fluoanthrene & $<0.0404$ & $<0.0404$ & $<0.0404$ & 0,02 & $<0.0404$ \\
8 & Pyrene & $<0.0404$ & $<0.0404$ & $<0.0404$ & 0,01 & $<0.0404$ \\
9 & Benzo(a)anthracene & $<0.004$ & $<0.004$ & $<0.004$ & $<0.004$ & $<0.004$ \\
10 & Chrysene & $<0.004$ & $<0.004$ & $<0.004$ & $<0.004$ & $<0.004$ \\
11 & Benzo(b)fluoranthene & $<0.008$ & $<0.008$ & $<0.008$ & $<0.008$ & $<0.008$ \\
12 & Benzo(k)fluoranthene & $<0.008$ & $<0.008$ & $<0.008$ & $<0.008$ & $<0.008$ \\
13 & Benzo(a)phyrene & $<0.008$ & $<0.008$ & $<0.008$ & $<0.008$ & $<0.008$ \\
14 & Indeno(1,2,3-cd)pyrene & $<0.008$ & $<0.008$ & $<0.008$ & $<0.008$ & $<0.008$ \\
15 & Dibenzo(a,h)anthracene & $<0.008$ & $<0.008$ & $<0.008$ & 0,09 & 0,14 \\
16 & Benzo(g,h,l)perylene & $<0.004$ & $<0.004$ & $<0.004$ & $<0.004$ & $<0.004$ \\
\hline 17 & Total PAH & ttd & ttd & 0,15 & 0,32 & 0.62 \\
\hline
\end{tabular}


Tabel 2. Jenis dan konsentrasi PAH pada sampel sedimen di lokasi penelitian

\begin{tabular}{llcccccccc}
\hline \multirow{2}{*}{ No. } & \multicolumn{1}{c}{ Jenis PAH } & \multicolumn{7}{c}{ Stasiun Penelitian dan Konsentrasi PAH (ppb) } \\
\cline { 3 - 9 } & & 1 & 2 & 3 & 4 & 5 & 6 & 7 & 8 \\
\hline 1 & Napthalene & $<0.0404$ & 3,53 & 71,29 & 44,17 & 7,07 & 8,64 & 304,24 & 330,99 \\
2 & Acenaphthylene & $<0.0404$ & $<0.0404$ & $<0.0404$ & $<0.0404$ & $<0.0404$ & $<0.0404$ & 3,68 & 3,41 \\
3 & Acenaphtene & $<0.0404$ & $<0.0404$ & $<0.0404$ & $<0.0404$ & $<0.0404$ & $<0.0404$ & $<0.0404$ & $<0.0404$ \\
4 & Fluorene & $<0.0404$ & 5,49 & 3,6 & $<0.0404$ & 3,19 & 16,04 & 15,49 & 16,04 \\
5 & Phenanthrene & 34,57 & 56,57 & $<0.0404$ & 3,05 & $<0.0404$ & 229,53 & 165,38 & 128,58 \\
6 & Anthracene & $<0.0404$ & $<0.0404$ & $<0.0404$ & $<0.0404$ & $<0.0404$ & $<0.0404$ & 5,59 & $<0.0404$ \\
7 & Fluoanthrene & $<0.0404$ & 15,7 & $<0.0404$ & 10,88 & $<0.0404$ & 46,67 & $<0.0404$ & 38,04 \\
8 & Pyrene & $<0.0404$ & 15,35 & 9,51 & 11,86 & $<0.0404$ & 41,67 & 54,31 & 32,46 \\
9 & Benzo(a)anthracene & $<0.004$ & $<0.004$ & $<0.004$ & 1,41 & $<0.004$ & $<0.004$ & $<0.004$ & $<0.004$ \\
10 & Chrysene & $<0.004$ & $<0.004$ & 2,61 & $<0.004$ & $<0.004$ & $<0.004$ & $<0.004$ & 8,89 \\
11 & Benzo(b)fluoranthene & $<0.008$ & $<0.008$ & $<0.008$ & $<0.008$ & $<0.008$ & $<0.008$ & $<0.008$ & $<0.008$ \\
12 & Benzo(k)fluoranthene & $<0.008$ & $<0.008$ & $<0.008$ & $<0.008$ & $<0.008$ & $<0.008$ & $<0.008$ & $<0.008$ \\
13 & Benzo(a)phyrene & $<0.008$ & $<0.008$ & $<0.008$ & $<0.008$ & $<0.008$ & $<0.008$ & $<0.008$ & $<0.008$ \\
14 & Indeno(1,2,3-cd)pyrene & $<0.008$ & $<0.008$ & $<0.008$ & $<0.008$ & $<0.008$ & $<0.008$ & $<0.008$ & $<0.008$ \\
15 & Dibenzo(a,h)anthracene & $<0.008$ & 2,95 & $<0.008$ & $<0.008$ & 1,66 & $<0.008$ & $<0.008$ & $<0.008$ \\
16 & Benzo(g,h,l)perylene & $<0.004$ & $<0.004$ & $<0.004$ & $<0.004$ & $<0.004$ & $<0.004$ & $<0.004$ & $<0.004$ \\
\hline 17 & Total PAH & 34,57 & 99,59 & 87,02 & 71,38 & 11,92 & 342,54 & 548,7 & 558,41 \\
\hline
\end{tabular}

Hal lain yang perlu mendapat perhatian penting adalah sumber PAH itu sendiri di perairan. Zakaria et al, (2006) menyebutkan bahwa sumber senyawa PAH di lingkungan perairan dapat berasal dari berbagai aktivitas baik aktivitas alami (perembesan minyak, asap kebakaran hutan, letusan gunung berapi) dan kegiatan manusia atau antropogenik seperti industri, transportasi dan rumah tangga. Muara Sungai Musi adalah daerah lalu lintas kapal baik kapal nelayan, kapal penumpang, kapal cargo maupun kapal-kapal pengangkut bahan kebutuhan sehari-hari masyarakat. Sumber PAH yang berasal dari aktifitas antropogenik seperti transportasi yang berlangsung secara terus menerus dapat menyebabkan terjadinya akumulasi konsentrasi PAH terutama pada sedimen perairan yang dalam jangka panjang akan mencemari organisme bentik yang hidup didalamnya. Uthe (1991) menyatakan bahwa senyawa PAH dapat terakumulasi dalam tubuh hewan tingkat rendah hingga mencapai kadar yang tinggi, karena sukar dicerna dalam tubuhnya

Hasil penelitian Putri et al., (2019) menemukan bahwa konsentrasi PAH di Muara Sungai Banyuasin yang berada satu kawasan dengan Muara Sungai Musi lebih kecil dibandingkan penelitian ini (pada sampel air 92,34320,09 ppb dan sedimen 3,16-23,28 ppb). Hal ini diduga disebabkan oleh aktivitas manusia di sekitar aliran sungai dan Muara Banyuasin lebih sedikit dibandingkan dengan aktivitas manusia di sepanjang aliran sungai dan Muara Sungai Musi. Beberapa hasil penelitian ditempat lain seperti Teluk Klabat (Kepulauan Bangka Belitung), kadar total PAH di perairan berkisar antara 0,375-44,486 ppb dengan rerata 7,468 ppb pada bulan Maret 2006. Adapun pada bulan Juli berkisar antara 1,329-27,826 ppb dengan rerata 15,2 ppb (Munawir, 2008). Falahudin et al., (2012) menemukan kadar PAH dalam sampel air yang berasal dari Laut Timor berkisar antara 54,6-213,7 ppb dengan rerata $99,7 \mathrm{ppb}$, sementara dalam sampel sedimen berkisar antara 23,6 to $24,5 \mathrm{mg} / \mathrm{kg}$ berat kering. Selanjutnya hasil penelitian Ahmad (2012) di Teluk Jakarta bagian barat menemukan kadar PAH berkisar antara 201,57-474,68 ppb dengan total kadar 1404,68 ppb. Untuk kawasan Teluk Jakarta bagian tengah kadar PAH berkisar antara104,61-337,07 ppb dengan total kadar 825,63 ppb. Adapun untuk kawasan timur kadar PAH berkisar 112,91-370,19 ppb dengan total kadar 806,73 ppb. Kawasan Teluk Jakarta bagian barat mempunyai kadar total $\mathrm{PAH}$ tertinggi dibandingkan dengan tengah dan timur, hal ini menunjukkan bahwa kawasan barat lebih banyak menerima masukan limbah PAH yang berasal dari aktivitas di darat dan laut. Achyani (2015) menyebutkan bahwa Perairan Tarakan terindikasi telah terkontaminasi PAH yang diduga berasal dari kegiatan sekitar pulau tersebut. Kadar total PAH dalam air dan sedimen di Perairan Tarakan berturut-turut berkisar antara 6,36-380 ppb dan 50$136 \mathrm{ppb}$, adapun konsentrasi PAH total dalam 
daging dan hati ikan nomei (H. neherus) berkisar antara 605-1067 ppb dan 977-1679 ppb. Selanjutnya, Lukitaningsih dan Sudarmanto (2010), menemukan kadar PAH dalam tubuh ikan petek (Chrorinomus lyson) berkisar antara 0,9310,9 ppb dan ikan Kuniran (Upeneus moluccensis) berkisar antara 1,9-1072,5 ppb yang berasal dari laut selatan Yogyakarta. Bila kerang dan ikan ini dimakan oleh manusia, maka PAH akan terakumulasi dalam tubuh manusia dan sampai pada batas tertentu dapat menimbulkan gangguan terhadap kesehatan manusia.

\section{KESIMPULAN}

PAH total dalam sampel air dan sedimen yang berasal dari Muara Sungai Musi dan sekitar Pulau Payung masih layak dan belum melebihi ambang batas yang diperkenankan. Terdapat 4 jenis komponen PAH yang ditemukan pada sampel air (Napthalene, Fluoanthrene, Pyrene serta Dibenzo(a,h) anthracene) dan10 jenis komponen PAH yang ditemukan dalam sampel sedimen selama penelitian yaitu jenis Napthalene, Acenaphthylene, Fluorene, Phenanthrene, Anthracene, Fluoanthrene, Pyrene, Benzo(a) anthracene, Chrysene, Dibenzo(a,h)anthracene

\section{DAFTAR PUSTAKA}

Achyani, R., Prartono T \& Riani E. 2015. Hidrokarbon Aromatik Polisiklik dalam Air dan Sedimen Laut serta Akumulasinya pada Ikan Nomei, Harpadon nehereus (Hamilton, 1822) Perairan Tarakan. Jurnal Iktiologi Indonesia, 15(3):267-282.

Ahmad F. 2012. Kandungan Senyawa Polisiklik Aromatik Hidrokarbon (PAH) di Teluk Jakarta. Jurnal Ilmu Kelautan, 17(4):199-208.

APHA, 2017. Standard Methods for examination of water and wastewater. $23^{\text {Rd }}$ Edition. American Public Health Association (APHA)-American Water Works Association (AWWA)-Water Environment Federation (WEF).

Edward. 2014. Senyawa Polisiklik Aromatik Hidrokarbon (PAH) dalam Air Laut di Teluk Jakarta. Depik. 3(3), 207-215.

Falahuddin, D., Munawir, K., Arifin, Z. \& Wagey G.A. 2012. Distribution and Sources of Polycyclic Aromatic Hydrocarbon (PAHs) in Coastal Waters of Timor Sea. Coastal Marine Science 35(1):112-121.
Keputusan Menteri Negara Lingkungan Hidup Nomor 51 Tahun 2004. Tentang baku mutu air laut. Jakarta. $10 \mathrm{hlm}$.

Lukitaningsih, E \& Sudarmanto, A. 2010. Bioakumulasi Senyawa Polisiklik Aromatik Hidrokarbon dalam Plankton, Ganggang dan Ikan di Perairan Laut Selatan Jogjakarta. Media Farmasi Indonesia, 21:18-26

Munawir, K. 2008. Kadar polisiklik Aromatik Hidrokarbon (PAH) dalam Air, Sedimen dan Sampel Biota di Perairan Teluk Klabat Bangka. Oseanologi dan Limnologi di Indonesia, 33:441-453.

Nasher, E., Heng L.Y., Zakaria Z \& Surif, S . 2013. Concentrations and Sources of Polycyclic Aromatic Hydrocarbons in the Seawater around Langkawi Island, Malaysia. Journal of Chemistry, 81:1-14.

Putri, W.A. E., Bengen, D. G., Prartono, T \& Riani, E. 2016. Accumulation of Heavy Metals $(\mathrm{Cu}$ and $\mathrm{Pb}$ ) in Two Consumed Fishes from Musi River Estuary, South Sumatera. Ilmu Kelautan, 21(1):45-52

Putri, W.A.E., Bengen, D.G., Prartono T \& Riani, E. 2015. Konsentrasi logam berat $(\mathrm{Cu}$ dan $\mathrm{Pb}) \mathrm{di}$ Sungai Musi Bagian Hilir. Jurnal Ilmu dan Teknologi Kelautan Tropis, 7(2):453-463.

Putri, W.A.E dan Purwiyanto, A.I.S. 2016. Konsentrasi $\mathrm{Cu}$ dan $\mathrm{Pb}$ dalam Air dan Plankton di Sungai Musi Bagian Hilir. J. Ilmu dan Teknologi Kelautan Tropis, 8(2):773-780.

Putri, W.A.E., Purwiyanto, A.I.S., Fauziyah, Agustriani, F. 2020. Identification Polycyclic Aromatic Hydrocarbons (PAHs) in the Banyuasin River Estuary, South Sumatera. IOP Conf. Series: Earth and Environmental Science 404:012038.

Simpson, L.A., G.E. Batley, A.A. Chariton, J.L. Stauber, C.K. King, J.C. Chapman, R.V. Hyne, S.A. Gale, A.C .Roach, W.A. Maher. 2005. Handbook for sediment quality assessment. Publish by Centre Environment Contamination Research. CSIRO Bangor-New South Wales.

Uthe, J.F. 1991. Polycyclic Aromatic Hydrocarbon in The Environment. Marine Chemistry Division, Departement of Fisher and Ocean. Halifax. Canadian Chemisal News, 25-27.

Zakaria, M.P \& Mahat, A.A. 2006. Distribution of Polycyclic Aromatic Hydrocarbon (PAHs) in Sediments in the Langet Estuary. Coastal Marine Science, 30(1):387-395. 